\title{
Representação social do namoro: a intimidade na visão dos jovens
}

\author{
Raquel Bohn Bertoldo 1 \\ Andréa Barbará2
}

\begin{abstract}
Resumo
Os relacionamentos íntimos, dentre eles o namoro, pressupõem a existência de identidades e representações sociais, que são compartilhadas através de comportamentos, normas e valores sociais. Objetivou-se identificar a representação social e a particularização em função da identidade sexual e experiência com o namoro. Para tal, a amostra foi composta por 183 estudantes universitários, com média de idade de 22 anos. Foi utilizado um questionário auto-aplicado em situação coletiva. $\mathrm{Na}$ análise dos dados foram utilizados os programas informáticos Evoc 2000, Similitude 2000, ALCESTE e SPSS. Os elementos da representação foram organizados em torno da noção de amizade descrita em termos de cumplicidade, confiança e amor. As garotas evocaram elementos relacionados à confiança e afeto e os garotos ao sexo. As pessoas que namoravam no momento representavam o namoro como uma relação de amizade e aceitação e os que haviam namorado no passado ressaltavam a questão da fidelidade e do compromisso.

Palavras-chave: Representações sociais; Análise estrutural; Namoro; Relações íntimas.
\end{abstract}

\section{Commitment's social representation: The intimacy in the youth view}

\begin{abstract}
The intimate relationships, between them the commitment, presuppose the existence of social identities and representations, shared though social behaviors, norms and values. Our aim was to identify the social representation and its particularizations in face of the sexual identity and the experience with committed relationships. 183 university students, with an average of 22 years, formed the sample. A self-applied questionnaire was used in a collective situation. In the data analysis were used the software Evoc 2000, Similitude 2000, ALCESTE and SPSS. The elements of the representation were organized around the notion of friendship and described in terms of complicity, trust and love. Girls brought more frequently elements related to trust and feelings whereas boys, to sex. People who were committed at the moment represented the commitment as relation of friendship and acceptance whereas those who had been committed in the past enhanced issues of fidelity and commitment.

Keywords: Social representations; Structural analysis; Commitment; Intimate relationships.
\end{abstract}

\section{Introdução}

O jovem adulto encontra-se tipicamente em uma fase de transição para a conquista da autonomia psicológica e emocional. Nesse sentido, as relações íntimas que se desenvolvem neste período - de amizade ou namoro - estabelecem um laço que confere segurança emocional neste momento de distanciamento das relações parentais. Para além do período final da adolescência, considera-se que a capacidade de construir e manter relações íntimas constitua um dos principais critérios de saúde mental e de satisfação interpessoal (Siqueira, 2001).

O namoro é caracterizado, sobretudo, pela estabilidade da associação entre duas pessoas, que é inversamente relacionado à probabilidade que uma pessoa vai deixar a relação. Refere-se à adesão de uma pessoa a uma relação específica mesmo quando fatores ambientais se interpõem contra a associação (Rodrigues,
Assmar \& Jablonski, 2002). Segundo Gonzaga, Kelner Londahl e Smith (2001), a presença momentânea e expressa de amor tem um papel crítico na aproximação entre parceiros ao assinalar e fortalecer compromisso e, conseqüentemente, promover comportamentos comprometidos e a percepção destes pelos parceiros.

Além da causalidade imbricada no surgimento do compromisso, é importante averiguar os motivos que mantêm os parceiros unidos. O comprometimento é descrito por Rodrigues e colaboradores (2002) de diversas maneiras: a) relacionado, primeiramente, a sentimentos de obrigação; b) posição na qual a decisão da pessoa com relação a alguma linha particular de ação tem conseqüências para outros interesses não relacionados à linha de ação, por razões estranhas à atividade em si; c) ou como uma atitude quanto à continuidade de uma relação que é potencializada pelos próprios atos da pessoa de investir nela tempo, esforço e recursos.

Endereço para correspondência:

${ }^{1}$ Universidade Federal de Santa Catarina

Rua Vereador Frederico Veras, 360 - Pantanal - 88040-200 - Florianópolis-SC - Telefone: (48) 3331-9067

E-mail: raquelbohn@gmail.com

${ }^{2}$ Rua José Serafim dos Santos, 97 - Barra da Lagoa - 88061-370 - Florianópolis 
Mesmo quando a relação compromissada é avaliada negativamente, muitos casais continuam unidos em vista de ganhos secundários relacionados à manutenção do compromisso. Isso acontece com base em mecanismos subjetivos de atenuação da dissonância cognitiva que tendem a aumentar os ganhos percebidos e amenizar cognitivamente as perdas observadas. Nesse sentido, relevar os investimentos feitos na relação, aumentar os custos do seu término, atrelar a relação ao autoconceito, reduzir a atratividade de relacionamentos alternativos e obter garantias privadas de lealdade e compromisso do parceiro são algumas alternativas que garantem estabilidade à relação (Rodrigues e colaboradores, 2002).

As reações íntimas vêm sofrendo bruscas modificações na história recente. É fato que o namoro, antes da revolução sexual, em geral, consistia em uma relação que antecedia o casamento, tinha duração relativamente curta e interações controladas pelos pais. Atualmente, no entanto, muitos tipos de relações interpessoais são designadas por este termo, desde uma relação curta e descompromissada até a co-habitação (Béjin, 1987). Nesse sentido, Ariès (1987), ao investigar relacionamentos de jovens parisienses nos anos 80, observou que, entre aqueles que co-habitavam, o casamento só era formalizado quando o casal passava a constituir família.

Mesmo com a variedade de tipos de relação que o termo namoro abarca atualmente, há um consenso conceitual diante do que Giddens (1994) delimita como "relacionamento puro", que define o tipo de relação presente nas gerações mais recentes. O relacionamento puro é um relacionamento centrado no compromisso, na confiança e na intimidade, de modo que os parceiros tenham garantias da estabilidade do relacionamento ao mesmo tempo que este deve durar enquanto for satisfatório para ambas as partes. Essa concepção de intimidade ganha relevância em face da relação de caráter romântico, mais freqüente antigamente, na qual o parceiro era idealizado e nele era projetado um futuro a ser compartilhado - a base da família nuclear tradicional. O relacionamento puro presume maior equilíbrio das relações de gênero, caracteriza uma parceria cujo foco é a relação e não responde às normas sociais, mas, sobretudo, ao respeito mútuo, promovendo a democratização das relações pessoais (Araújo, 2002). No mesmo sentido, Araújo (2003), tomando por base um estudo sobre o amor no feminino, conclui que entre as mulheres o que é apreendido como amor agrega fundamentalmente $\mathrm{O}$ erotismo e a alegria da amizade.

Já em relação à diferenciação da relação amorosa por gênero, Rieth (2002) observa quanto à iniciação sexual de adolescentes, que as mulheres vinculam no namoro amor e sexo, em um relacionamento com a "pessoa certa"; já para os homens, a relação de namoro não é necessária, pois a experiência sexual não pressupõe vínculo afetivo - buscam se afirmar enquanto indivíduos ante os outros com a experiência da sexualidade. Justo (2005) apresenta o namoro dos dias de hoje como uma etapa de relacionamento posterior ao "ficar" e, se considerado uma relação estável, traz ao jovem o conflito entre a promessa de segurança, fidelidade, confiabilidade, durabilidade e a promessa de independência, autonomia, realização e diversidade.

É desse modo evidente que as representações sobre a individualidade e, conseqüentemente, sobre as relações interpessoais e conjugais fazem parte de um contexto social socialmente compartilhado. Neste contexto, ganha relevância e sentido para a investigação das relações íntimas a análise das representações sociais a elas vinculadas.

\section{A Teoria das Representações Sociais}

$\mathrm{O}$ que constitui o ponto de partida para esta teoria é o abandono da distinção clássica entre sujeito e objeto. Moscovici (1976) aponta que "não existe separação entre o universo externo e o universo interno do indivíduo (ou do grupo). Sujeito e objeto não são forçosamente distintos", isto é, segundo o processo de representação, há um continuum entre o sujeito e o objeto, havendo, deste modo, uma construção ativa do objeto por parte do sujeito por meio da representação. Além de modular o estímulo que o sujeito recebe, a representação também é ativa e direciona a resposta do sujeito, seu comportamento (Vala, 1996).

Desse modo, Abric (1998) afirma que não existe uma realidade objetiva a priori, mas sim que

[...] toda a realidade é representada, quer dizer, re-
apropriada pelo individuo ou pelo grupo, reconstruida
em seu sistema cognitivo, integrada no seu sistema de
valores, dependente de sua história e do contexto
ideológico e social que o cerca (p. 27$)$.

Pode-se aí perceber o caráter diretivo da ação presente na noção de representações sociais. Jodelet (1989) conceitua as representações sociais como "uma modalidade de conhecimento, socialmente elaborada e partilhada, que tem um objetivo prático e concorre para a construção de uma realidade comum a um conjunto social" (p. 36).

Bauer (1995) aponta a resistência como parte essencial da pragmática das representações sociais,

Psico-USF, v. 11, n. 2, p. 229-237, jul./ dez. 2006 
mantendo a heterogeneidade no contexto intergrupal. Assim, acabam persistindo subculturas que resistem a inovações que elas não produziram, formando reapresentações, as quais agem como um sistema imunológico cultural de modo que novas idéias são assimiladas por aquelas já existentes. Então, elementos que não eram familiares tornam-se familiares dentro de um sistema simbólico internamente coerente com valores, normas culturais e com a história do grupo.

Ao explicar o processo de formação das representações sociais, Moscovici salienta dois processos maiores: a ancoragem e a objetivação. Esta corresponde à forma como se organizam os elementos de uma representação social e o percurso através do qual adquirem materialidade, processo que envolve três momentos. Primeiramente as informações, idéias e crenças acerca de um objeto são selecionadas e descontextualizadas e estes são reorganizados em torno de um esquema estruturante. A última etapa deste processo consiste na naturalização, de modo que as relações estabelecidas se constituam como categorias naturais e adquiram materialidade. Já a ancoragem refere-se ao fato de tudo o que se pensa sobre alguma coisa ter um embasamento na realidade. Quando pensa sobre um objeto, o sujeito usa como referência experiências e esquemas de pensamento já estabelecidos. Desse modo, a ancoragem assemelha-se a um processo de categorização, uma vez que atribui aos objetos um local dentro de uma malha de significados (Vala, 1996; Moscovici, 1978).

A análise do conteúdo das representações sociais pode ser feita sob três dimensões: a informacional (referente à quantidade e qualidade de informações que se dispõe sobre o objeto em questão) a do campo (relativa à organização do seu conteúdo e suas propriedades qualitativas e figurativas) e a da atitude (remetendo às orientações positivas ou negativas diante do aspecto do objeto) (Moscovici, 2003).

\section{A abordagem estrutural: a Teoria do Núcleo Central}

Segundo Abric (1998), uma representação é constituída de um conjunto de informações, crenças, opiniões e atitudes a propósito de um dado objeto social. Estas informações organizam-se em torno de uma estrutura, constituindo um sistema sociocognitivo específico, no centro de cuja estrutura figura o núcleo central que confere à representação seu significado.

É o núcleo central que singulariza a representação, individualizando-a. Se há uma modificação no núcleo central, pode-se dizer que há uma modificação na representação como um todo, ou seja, mesmo que uma representação mude de estrutura, mantendo o mesmo núcleo central, pode-se dizer que se Psico-USF, v. 11, n. 2, p. 229-237, jul./ dez. 2006 trata da mesma representação, mas quando aquele muda, mesmo que a estrutura continue a mesma, tem-se uma modificação na representação como um todo.

O núcleo central é determinado, de um lado, pela natureza do objeto representado; de outro, pelo tipo de relações que o grupo mantêm com este objeto e, enfim, pelo sistema de normas sociais que constituem o meio ambiente ideológico do momento e do grupo (Abric, 1998). É o elemento mais estável da representação, aquele que assegura a continuidade em contextos móveis e evolutivos.

O núcleo central possui duas funções fundamentais: (1) função geradora: é a partir do núcleo central que se criam ou se transformam os significados dos outros elementos da representação; (2) função organizadora: determina a natureza da conjunção entre os elementos da representação, sendo, portanto, unificador e estabilizador.

Deve-se atentar para o fato de não ser a centralidade um aspecto definido por critérios puramente quantitativos, de modo que não é a presença maciça de um elemento que define a sua centralidade, mas sim o fato de que ele dá significado à representação.

Os elementos periféricos organizam-se em torno do núcleo central e constituem os elementos mais concretos, acessíveis e vivos. São eles que ajustam a representação, com seu núcleo central mais estável e característico, à realidade e às práticas sociais de um grupo. Flament (1994) atribui aos elementos periféricos a função de prescritores de comportamentos, indicando ao sujeito espontaneamente como agir em um determinado contexto. A modulação personalizada da representação refere-se à apropriação individualizada em contextos específicos, o que dá lugar a diferenças aparentes - desde que esses elementos estejam organizados em torno de um mesmo núcleo central.

\section{Identidade social e gênero}

Compartilhando da Teoria das Representações Sociais de Moscovici e das formulações sobre a Identidade Social de Tajfel, partiu-se do pressuposto de que os indivíduos, desde o momento em que realizam atividade simbólica, funcionam dentro de certas identidades sociais a partir das quais reconstroem, por eles mesmos, as representações sociais dos outros grupos presentes na sua sociedade (Lloyd, 1994). Dessa forma, a expressão de uma identidade social traz em si uma particularização da representação social que aconteceu em virtude da dinâmica das relações intergrupais na sociedade (homem/mulher, católicos/ protestantes, negros/brancos e assim por diante). A identidade social apresenta três caracte-rísticas 
importantes: a) é compartilhada; b) depende da pertença do indivíduo à uma categoria social e c) comporta uma carga emocional assim como valores ligados a essa pertença (Tajfel, 1982).

Tendo como premissa que a entrada para a escola é um momento de reconstituição das identidades sexuais, derivada da teoria das ações comunicativas, Lloyd (1994) observou em crianças no primeiro ano de escolarização o desenvolvimento de grupos claramente definidos segundo o sexo e as identidades sexuais que os distinguem no interior de cada grupo. Foram verificadas diferenças entre os jogos preferidos de acordo com o sexo somente no final do primeiro ano escolar, mesmo assim moderadas pela cultura compartilhada em cada sala de aula, caracterizando uma particularização da representação compartilhada de acordo com o grupo de pertença.

Nesse sentido, é a noção compartilhada do que constitui o feminino e o masculino (representação social), particularizada pela identidade social de cada indivíduo, que indica seus valores e comportamentos. Da mesma maneira, as identidades sociais masculina e feminina são renegociadas no ambiente privado de uma relação íntima, pois são básicas para a particularização de outra representação social: a da própria relação.

O presente estudo caracteriza-se por uma análise estrutural das representações sociais do namoro. Deste modo, objetivou-se caracterizar o conteúdo dessas representações, bem como sua estrutura, a partir da análise dos elementos evocados e das relações existentes entre eles.

\section{Método}

\section{Participantes}

A amostra foi composta por 183 alunos da Universidade Federal de Santa Catarina, sendo 72 do sexo feminino e 111 do sexo masculino, divididos em dois subgrupos: ciências humanas (psicologia, ciências sociais, pedagogia, serviço social e história), que compõe 36\% da amostra, e ciências exatas (engenharia elétrica, física, química, computação, engenharia de aqüicultura e engenharia sanitária), 64\% da amostra. A média de idade dos participantes foi de 22 anos e, da totalidade dos estudantes, 43\% declararam estar namorando no momento da pesquisa, 53\% já tinham namorado anteriormente e 13\% nunca namoraram. A média do tempo de relação dos alunos que estavam namorando no momento foi de um ano.

\section{Instrumentos}

O instrumento utilizado foi um questionário auto-aplicado, composto por quatro partes: (1) dados de identificação - sexo, idade (indicada em anos e meses) e curso; (2) evocação - apresentando como estímulo indutor à palavra namoro, depois do que foi solicitado aos estudantes que indicassem dentre as evocações as duas palavras que julgavam de maior importância; (3) experiência do sujeito com o objeto - a) se estavam namorando no momento da pesquisa; se sim, por quanto tempo; b) se já haviam namorado; se sim, quanto tempo durou a relação mais longa; (4) questão aberta, onde se pedia a redação de um parágrafo sobre o namoro.

\section{Análise de dados}

A análise dos dados obtidos pelo teste de associação livre sobre "namoro" é lexicográfica, isto é, considera a freqüência e a ordem de evocação das palavras. Esses critérios permitem uma aproximação da noção de prototipicidade dos elementos de uma representação. Para tal fim foram utilizados os programas informáticos Evocation 2000 (Scano, Junique \& Vergès, 2002) e Similitude 2000 (Junique, Barbry, Scano, Zeliger \& Vergès, 2002). As evocações foram então agrupadas em categorias semanticamente próximas e essas, analisadas por ambos os programas.

O programa Evocation 2000 fornece hipóteses de elementos que constituem o núcleo central da representação, portanto, carece de uma análise confirmatória. Para este fim, foi pedido ao respondente que indicasse as duas evocações que considerava mais importantes. As palavras marcadas como mais importantes por no mínimo 50\% dos respondentes foram confirmadas como parte integrante do núcleo central.

O programa Similitude 2000 busca uma visualização da conexidade dos elementos que participam da composição prototípica do núcleo central das representações sociais do namoro. Esta técnica se baseia na teoria dos grafos, que utiliza a relação de ligação pareada de variáveis. Ela baseia-se na afirmação de Moliner (1994) de que "não é porque uma cognição é fortemente ligada a outras que é central, mas por ser central é que está ligada a outras".

Para a análise da questão aberta foi utilizado o software Alceste - Analyse lexicale par contexte d'um ensemble de segments de texte (Reinert, 1998). Este programa realiza uma "análise hierárquica descendente que oferece contextos textuais que são caracterizados pelo seu vocabulário, e também por segmentos de texto que compartilham esse vocabulário" (Nascimento-Schulze \& Camargo, 2000, p. 297). O programa divide o corpus em UCI (Unidade de Contexto Inicial), que corresponde à resposta de um indivíduo, e em UCE (Unidade de Contexto Elementar), segmentos do texto que Psico-USF, v. 11, n. 2, p. 229-237, jul./dez. 2006 
constituem o ambiente da palavra. O texto, ao final da análise, está dividido em classes de UCEs. Foi realizada uma primeira análise standart e a segunda comparou os dados da amostra feminina e masculina - análise triscroisés. Já na análise descritiva dos dados demográficos e de identificação foi utilizado o programa SPSS.

\section{Resultados e discussão}

\section{Teste de Evocação Livre}

Foi obtido um total de 912 evocações, e 147 palavras diferentes. As evocações que mantinham uma proximidade semântica foram agrupadas em 29 categorias. Essas categorias tiveram uma média de 30,5 evocações, feitas, em média, na $3^{a}$ das cinco evocações solicitadas.

Como pode-se observar na Tabela 1, o possível núcleo central da representação do namoro é caracterizado pelos elementos amor, carinho, companheirismo, amizade e compromisso. Essas noções formam, para esse grupo, a noção central do que consiste esse tipo de relação. As categorias sexo, fidelidade, beijo e ciúme, apesar de representarem noções importantes para pensar o namoro, parecem estar ligadas a aspectos mais pragmáticos da representação que se encontram na interface do núcleo central com o ambiente e com o comportamento do indivíduo.

Tabela 1 - Possíveis elementos constituintes do núcleo central

\begin{tabular}{lcclcc}
\hline & & OME*<3,0 & OME $\geq 3,0$ & & \\
\hline Amor & 114 & 2,3 & Confiança & 86 & 3,3 \\
Carinho & 87 & 2,9 & Sexo & 85 & 3,0 \\
Companheirismo & 60 & 2,8 & Respeito & 41 & 3,3 \\
Amizade & 55 & 2,7 & Compreensão & 39 & 3,2 \\
Compromisso & 34 & 2,9 & Fidelidade & 35 & 3,5 \\
F $\geq 30,5$ & & Sinceridade & 31 & 3,1 \\
& & & & \\
F $<30,5$ & & & & \\
Beijo & & Paixão & 27 & 3,0 \\
Intimidade & 20 & 2,0 & Alegria & 21 & 3,7 \\
Namorado(a) & 15 & 2,9 & Afeto & 19 & 3,2 \\
Privação & 13 & 2,4 & Diversão & 13 & 3,8 \\
Estabilidade & 8 & 2,5 & Prazer & 10 & 3,2 \\
Saudade & 8 & 2,5 & Brigas & 10 & 3,8 \\
& 7 & 2,0 & Responsabilidade & 9 & 3,5 \\
& & Ciúme & 9 & 3,6 \\
& & Paciência & 8 & 4,1 \\
& & União & 8 & 4,1 \\
& & & Traição & 6 & 3,8 \\
& & & Aprendizado & 5 & 3,8 \\
\hline
\end{tabular}

*OME: Ordem média de evocação

A análise do núcleo central apresenta noções compatíveis com o conceito de relacionamento atualmente mais comum, segundo o qual a estabilidade das relações íntimas deve-se ao compromisso, à confiança, à intimidade, ao amor e à amizade (Giddens, 1994). O sistema periférico apresenta noções que permeiam as relações conceituadas pelo núcleo, na relação dos indivíduos na cotidianidade, bem como seus embates e negociações íntimas (Justo, 2005).

A análise diferencial das evocações entre homens e mulheres apresentou algumas diferenças significativas quanto às palavras. As mulheres evocaram mais freqüentemente as palavras: carinho $(\mathrm{t}$ de Student $=1,64)$, companheirismo $(2,44)$, cumplicidade $(2,88)$ e sinceridade $(2,62)$, enquanto os homens evocaram mais vezes a palavra sexo $(2,16)$. Esses resultados parecem corroborar as conclusões de (Rieth, 2002) sobre o que homens e mulheres jovens buscam em um relacionamento como o namoro.

\section{Análise de Similitude}

A análise da co-ocorrência das categorias permite a visualização da organização da representação social a partir da força com que os elementos ligam-se uns aos outros. Assim, obtém-se uma árvore máxima que mostra a centralidade e a conexidade dos diversos elementos. 
O exame da organização da representação social do namoro nos permite observar a centralidade da noção de amizade, como pode ser observado na Figura 1.

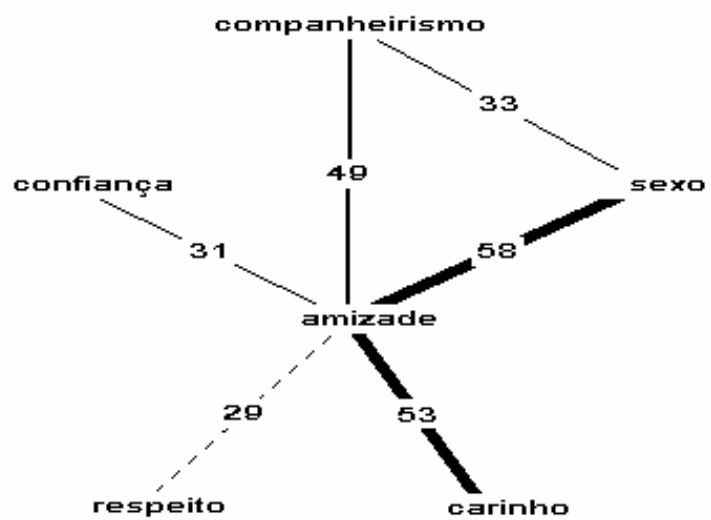

Figura 1 - Árvore máxima de clique 27
O elemento amizade, apesar de não ser o mais freqüente na amostra, apresenta-se como organizador dos outros elementos da representação, uma vez que mantêm uma forte conexidade com eles. Portanto, podese afirmar que a noção de amizade é central para a representação social do namoro, já que organiza os outros elementos em seu redor e mantêm com eles forte conexidade. Apesar de ter sido a categoria mais evocada, o elemento amor apresenta fraca conexão com os outros elementos, o que o descaracteriza como elemento central, apesar de ser um elemento importante. Esses resultados confirmam o tipo de relacionamento amoroso ideal para as mulheres - que alie amor erótico à alegria e humor da amizade (Araújo, 2003).

\section{Análise hierárquica descendente}

A análise lexical realizada baseada no programa Alceste confirma os resultados acima apresentados. A analise hierárquica descendente realizada por meio do programa ALCESTE, dividiu em 3 classes as respostas dos participantes sobre o significado do namoro, com pode ser observado na Figura 2:

\begin{tabular}{|c|c|c|c|c|c|c|c|c|}
\hline \multirow{2}{*}{\multicolumn{3}{|c|}{$\begin{array}{l}\text { Classe 1: Relação de compromisso e } \\
\text { fidelidade } \\
29 \text { UCE - } 16,57 \% \\
\text { Variáveis descritivas: } \\
\text { - Namorou no passado; } \\
\text { Palavras de maior associação: }\end{array}$}} & \multicolumn{3}{|c|}{$\begin{array}{l}\text { Classe 3: Descrição da relação } \\
69 \mathrm{UCE}-39,43 \% \\
\text { Palavras de maior as sociação: }\end{array}$} & \multirow{3}{*}{\multicolumn{3}{|c|}{$\begin{array}{l}\text { Classe 2: Relação de amixade e } \\
\text { aceitação } \\
77 \text { UCE - } 44 \% \\
\text { Variáveis descritivas: } \\
\text { - Namora no momento; } \\
\text { - Nunca namorou. } \\
\text { Palavras de maior associação: }\end{array}$}} \\
\hline & & & Palavras & Freqüuência & $x^{2}$ & & & \\
\hline Palavras & Freqülência & $x^{2}$ & Respeito & 41 & 6,23 & & & \\
\hline Compromisso & 138 & 8,88 & Confiança & 39 & 6,06 & Palavras & Freqüuência & $x^{2}$ \\
\hline Intimidade & 40 & 6,76 & Deve & 32 & 6,52 & Vida & 28 & 5,57 \\
\hline Fidelidade & 22 & 7,13 & Cumplicidade & 22 & 15,09 & Importante & 27 & 4,66 \\
\hline Envolvimento & 19 & 33,46 & Sincera & 20 & 4,00 & Tempo & 26 & 5,67 \\
\hline \multirow[t]{11}{*}{ Companhia } & \multirow[t]{11}{*}{6} & \multirow[t]{11}{*}{20,03} & Exista & 15 & 11,31 & Contar & 10 & 9,11 \\
\hline & & & Afeto & 13 & 12,01 & Preocupar & 10 & 9,11 \\
\hline & & & Baseado & 11 & 8,83 & Procura & 10 & 9,11 \\
\hline & & & Paixão & 11 & 8,83 & Problema & 10 & 4,39 \\
\hline & & & Casal & 10 & 4,15 & Aceitar & 8 & 6,44 \\
\hline & & & Dificil & 10 & 4,15 & Satisfaz & 8 & 6,44 \\
\hline & & & Liberdade & 10 & 4,15 & Compreensão & 7 & 9,28 \\
\hline & & & Durar & 9 & 9,72 & Defeitos & 6 & 7,91 \\
\hline & & & Haja & 7 & 6,54 & Rixim & h & 791 \\
\hline & & & Fator & 6 & 9,54 & & & \\
\hline & & & Manter & 6 & 5,01 & & & \\
\hline
\end{tabular}

Figura 2 - Dendograma das classificações hierárquicas descendentes de questão aberta sobre o que constitui o namoro 
A análise hierárquica descendente mostrou que a representação social do namoro é globalmente compartilhada (classe 3) como uma relação de cumplicidade e confiança baseada em amor, na qual há respeito pelas diferenças, recaindo a ênfase, sobretudo, na sinceridade - o que não foge da caracterização de uma relação de amizade -, noção que, de acordo com a análise do campo da representação social, a organiza e significa.

A classe 1 apresenta um discurso sobre o namoro mais focado na fidelidade, como relação compromissada que cria intimidade e visa à felicidade mútua mediante o respeito pela individualidade de cada parceiro. Esta classe é compartilhada por alunos que haviam namorado no passado e não estavam namorando no momento da pesquisa, de modo que a representação global do namoro ganha esta particularização em razão da vivência do sujeito com o objeto da representação, que faz com que alguns elementos fiquem em evidência, como a questão do compromisso. Como um mecanismo de adaptação cognitiva à situação de estar só (Rodrigues e colaboradores, 2002), o indivíduo aqui parece ressaltar os aspectos negativos de uma relação comprometida (Justo, 2005).

A classe 2 caracteriza o namoro por uma relação de amizade que propicia conhecer o parceiro nos seus defeitos e aceitá-los, parceiro com quem se pode contar nos momentos difíceis, tudo isso aliado à atração física, sexo. Essa classe foi dividida por jovens que namoravam no momento da pesquisa e por aqueles que nunca haviam namorado. Esta particularização parece estar ligada à idealização que esses jovens em particular fazem da relação: os jovens que nunca namoraram, por não terem tido contato com o objeto, e os que namoram, como uma reestruturação cognitiva que suaviza algum ponto negativo do seu cotidiano, visando a um contato mais afável com sua realidade (Rodrigues e colaboradores, 2002).

$\mathrm{Na}$ análise tris-croisés surgiram diferenças significativas do material da amostra feminina e masculina. Os homens descreveram o namoro de forma racionalmente distanciada da sua realidade, explicando no que consiste essa relação a partir de um casal ideal (palavras associadas: busca, casal, consiste, exemplo, interessante). As mulheres fizeram uma descrição do objeto mais relacional, utilizando adjetivos que implicavam o próprio envolvimento emocional, relacionando-se com a representação (palavras associadas: amor, aprender, carinho, ceder, cumplicidade, dar, envolve, reciprocidade, sentir, e sinceridade).

Observou-se assim que a vivência com o objeto da representação é o que fundamentalmente vai Psico-USF, v. 11, n. 2, p. 229-237, jul./ dez. 2006 diferenciar a representação social. O gênero é uma variável que denota papéis, valores e comportamentos adequados. A experiência pregressa e atual do namoro parece relativizar alguns elementos da representação e aciona outros, de maneira que o indivíduo possa organizar sua realidade reinterpretando aspectos pouco agradáveis.

Pode-se assim perceber o quanto as relações íntimas, em especial o namoro, são pensadas com base em representações compartilhadas e, apesar de homens e mulheres conservarem papéis sociais específicos de sua cultura, sustentam globalmente uma representação do namoro ligada à parceria, à amizade, revelando deste modo um pacto de mutualidade que dura enquanto a relação satisfizer a ambos. Contrapõe-se à idéia de amor romântico, segundo o qual existiria uma pessoa certa a quem se deveria amar eternamente. Apesar de apontar para a igualdade diante da relação, homens e mulheres apresentam identidades sociais que emergem no comportamento socialmente orientado.

\section{Conclusão}

Tendo como base a teoria das representações sociais, deve-se destacar a característica peculiar do nosso objeto de investigação. Por ser um tipo de interação, a noção de namoro implica diversas componentes identitárias socialmente compartilhadas que indicam ao indivíduo seus valores, comportamentos e atitudes em relação ao seu grupo e àquele em oposição ao qual o seu é identificado. Assim, homens e mulheres compartilham identidades sexuais ao mesmo tempo em que particularizam a representação social não só de femini-lidade e masculinidade, mas da relação intersubjetiva entre eles.

A centralidade do elemento amizade, bem como o seu papel estruturador da representação do namoro, apontam para a representação de uma relação igualitária, na qual são renegociadas identidades sociais tanto intra quanto intersubjetivamente. Esta configuração de relacionamento compromissado vai ao encontro do que Giddens (1994) chama de "relacionamento puro", que se baseia no compromisso, confiança e intimidade. A noção de amor, que foi a mais freqüentemente evocada, e, portanto, aparentemente central, tem neste campo representacional um papel subalterno, ligado sobretudo a idéias de indissolubilidade do relacionamento.

Mesmo dentro de um novo contexto onde a relação é negociada, homens e mulheres têm claras distinções representacionais da relação. Corroborando Rieth (2002), foram encontradas representações diferentes de acordo com o sexo, confirmando o estereótipo feminino relacional e emocional; e o 
masculino, racional e afirmativo. É por meio das identidades sociais do que é ser mulher e do que é ser homem, e das representações compartilhadas nestes contextos que esses homens e mulheres cresceram, desenvolveram suas atitudes, bem como construíram expectativas uns em relação aos outros.

Dessa forma, apesar de haver uma representação central do que é elaborado coletivamente como namoro, estão implicados diretamente papéis sociais que são socialmente construídos e compartilhados. Fica evidente como, apesar das mudanças que têm ocorrido em torno das identidades sociais, as suas noções e comportamentos são guiados e construídos a partir das mesmas bases sociais, há muito instauradas e reconstruídas até os dias de hoje. O comportamento serve tanto como produto quanto como produtor dessas diferenças que há muito permeiam as nossas relações e, mesmo assim, tomam ar de novidade (Poeshl, 2003).

\section{Referências}

Abric, J. C. (1998). A abordagem estrutural das representações sociais. Em A. S. P. Moreira \& D. C. Oliveira. (Orgs.). Estudos interdisciplinares de representação social (pp. 27-38). Goiânia: AB.

Araújo, D. R. D. (2003). O amor no feminino: ocultamento e/ou revelação. Estudos de Psicologia, 8(3), 469-477.

Araújo, M. F. (2002). Amor, casamento e sexualidade. Psicologia: Ciência e Profissão, 22(2), 70-77.

Ariès, P. (1987). O amor no casamento. Em P. Ariès \& A. Béjin (Orgs.). Sexualidades ocidentais (pp. 153-82). São Paulo: Brasiliense.

Bauer, M. (1995). Popularização da ciência como "imunização cultural": a função de resistência das representações sociais. Em P. Guareschi \& S. Jovchelovitch (Orgs.). Textos em representacooes sociais (pp. 229-257). Petrópolis: Vozes.

Béjin, A. (1987). O casamento extraconjugal dos dias de hoje. Em P. Ariès \& A. Béjin (Orgs.). Sexualidades ocidentais (pp. 183-193). São Paulo: Brasiliense.

Flament, C. (1994). Aspects périphériques des représentations sociales. Em C. Guimelli (Org.). Structures et transformations des représentations sociales (pp. 85-118). Lousanne: Delachaux et Nieltlé.

Giddens, A (1994). A transformação da intimidade: sexualidade, amor e erotismo nas sociedades modernas. São Paulo: UNESP.
Gonzaga, G. C., Kelner, D., Londahl, E. A. \& Smith, M. D. (2001). Love and the commitment problem in romantic relations and friendship. Journal of Personality and Social Psychology, 81(2), 247-262.

Jodelet, D. (1989). Les représentations sociales: un domaine en expansion. Em D. Jodelet (Org.). Les représentations sociales (pp. 31-61). Paris: PUF.

Junique, C., Barbry, W., Scano, S., Zeliger, R. \& Vergès, P. (2002). L'analyse de similitude de questionnaires et de données numériques, SIMI2000. Manuel d'utilsateur. Aix em Provence.

Justo, J. S. (2005). O "ficar" na adolescência e paradigmas de relacionamento amoroso da contemporaneidade. Revista do Departamento de Psicologia - UFF, 17(1), 61-77.

Lloyd, B. (1994). Différences entre sexes. Em S. Moscovici (Org.). Psychologie sociale des relations à autrui (pp. 280-296). Paris: Nathan.

Moliner, P. (1994) Les méthodes de repérage et d'identification du noyau des représentations sociales. Em C. Guimelli (Org.). Structures et transformations des représentations sociales (pp. 199-232). Lausanne: Delachaux \& Niestlé.

Moscovici, S. (1976). La psychanalyse, son image et son public. Paris: PUF.

Moscovici, S. (1978). A representação social da psicanálise. Rio de Janeiro: Zahar.

Moscovici, S. (2003). O fenômeno das representações sociais. Em S. Moscovici (Org.). Representaçoes sociais: investigaçoes em psicologia social (pp. 29-110). Petrópolis: Vozes.

Nascimento-Schulze, C. \& Camargo, B. V. (2000). Psicologia social, representações sociais e métodos. Temas em Psicologia, 8(3), 287-299.

Poeshl, G. (2003). Representações das diferenças entre os sexos, práticas familiares e relações entre homens e mulheres. Estudos Vida e Saúde, 30(1), 31-50.

Reinert, M. (1998). Alceste: Analyse de données textuelles. Manuel d'utilisateur. Toulouse: IMAGE.

Rieth, F. (2002). A iniciação sexual na juventude de mulheres e homens. Horizontes Antropológicos, 8(17), 77-91.

Rodrigues, A., Assmar, E. M. L. \& Jablonski, B. (2002). Psicologia social. Petrópolis: Vozes.

Tajfel, H. (1982). Social identity and intergroup relations. Cambridge: Cambridge University Press. 
Scano, S., Junique, C. \& Vergès, P. (2002). Ensemble de programmes permettant l'analyse des évocations, EVOC2000. Manuel d'utilsateur. Aix em Provence.

Siqueira, R. M. O (2001). Representaçoes sociais de jovens estudantes do ensino médio em Itajai/SC, sobre relações intimas no contexto da AIDS (Dissertação de Mestrado). Florianópolis: Universidade Federal de Santa Catarina - Programa de Pós-Graduação em Psicologia.
Vala, J. (1996). Representações sociais: para uma psicologia social do pensamento social. Em J. Vala \& M. B. Monteiro (Orgs.). Psicologia social (pp. 353-384). Lisboa: Fundação Caluste Gulbenkian.

Recebido em outubro de 2005 Reformulado em setembro de 2006 Aprovado em outubro de 2006

Sobre as autoras:

Raquel Bohn Bertoldo é bacharel em Psicologia pela UFSC e bolsista de Iniciação Científica do CNPq do Laboratório de Psicossociologia da Comunicação e da Cognição Social (LACCOS).

Andréa Barbará é psicóloga e doutoranda do Programa de Pós-Graduação em Psicologia da Universidade Federal de Santa Catarina. 
